\title{
BIENAL TLATELOLCA
}

JOSÉ ANTONIO MONROY Y BALAM BARTOLOME

tlatelolcobienal@gmail.com | cabezilapiz@gmail.com

http://bienaltlatelolca.org/

A

I hacer un mapa proyectamos gráfica y simbólicamente la escala de valores que establecemos sobre un territorio. Esto se construye a partir de una perspectiva del espacio multidimensional esférico traducido a un código gráfico bidimensional. La cartografía que hacemos con respecto al espacio habitado propone la aprehensión del mundo en términos simbólicos, culturales y geopolíticos.

El Conjunto Habitacional Nonoalco Tlatelolco, en la Ciudad de México, se erige en lo que alguna vez fue el islote de Xaltelolco, lugar donde se afincó la ciudad homónima. Tlatelolco ha sido protagonista de distintos periodos de esplendor y caída desde su creación y hasta nuestros días. Basta mencionar su importancia como vórtice político y económico de Mesoamérica, su papel protagónico en la generación y distribución de conocimiento del "Nuevo" al "Viejo Mundo", el hecho de ser el primer proyecto Moderno de América Latina, su consecuente abandono y la distopía que arrastra consigo, así como la especulación a la que se ve sometida actualmente bajo el modelo económico mundial y su ejercicio brutal del capital.

Bajo estos antecedentes, y reconociendo a Tlatelolco como un potente generador y portador de la estructura cultural de México, los artistas Balam Bartolomé (Ocosingo, 1975) y Antonio Monroy (Toluca, 1984), decidieron plantear un formato de producción y pensamiento artístico que, bajo el nombre de Bienal Tlatelolca, conecta el espacio físico, cultural y simbólico a partir de una urdimbre metafórica dentro y alrededor del área que comprende la unidad habitacional, símbolo de la distopía nacional alrededor de la modernidad.

El proyecto se divide en dos etapas. La primera se desarrolla bajo el formato de residencias artísticas con duración de 2 meses. La Bienal Tlatelolca privilegia la investigación y plantea sus residencias como procesos seminales, no conclusivos, donde los artistas fueron invitados a proponer distintos eventos - estudios abiertos, charlas, derivas, convivencias comunitarias, proyecciones, etc. -, que enriquecieran su investigación alrededor de los ejes de pensamiento establecidos por la Bienal. La segunda fase consiste en un evento de formato bienal —con fecha programada en 2021-, donde se incluirá el resultado de los 
participantes de la primera fase, más otros artistas que se irán sumando en el camino. El propósito es ahondar, desde el proceso artístico, la relación que puede hacerse con el territorio tlatelolca, bajo los siguientes ejes:

1. Mesoamérica-América-Latinoamérica: Territorio-Geografía-Identidad

2. Matria-Patria: Naturaleza-Cultura-Memoria

3. Colonia-Independencia: Explotación-Autonomía

4. Revolución-Modernidad: Nación-Imperialismo-Globalización

Los artistas operan bajo la figura mesoamericana del "tlacuilo", mujeres y hombres que eran educados desde pequeños para registrar, a través del dibujo, los mitos, genealogía, historia y política de su sociedad. Esto los obligaba a conocer sobre temas fundamentales: mitología, astronomía, zoología, botánica, historia, geografía, etc., lo que en la actualidad veríamos como la estructura del conocimiento.

Los artistas participantes durante el período 2019-2020 fueron: Dulce Chacón, Cristóbal Gracia, Miriam Salado, Mazenett \& Quiroga, Arturo Hernández Alcázar, Victoria Núñez, Erik Tlaseca y Laura Valencia Lozada.

Con respecto al impacto que la pandemia de COVID-19 ha tenido en las actividades culturales, los coordinadores de la Bienal Tlatelolca consideraron importante compensar este hecho con propuestas creativas dentro de la emergencia, para continuar compartiendo y discutiendo temas que, ahora más que nunca, resultan de importancia. Ante la imposibilidad de realizar estudios abiertos y visitas de estudio, se decidió llevar a cabo lo siguiente:

1. Conversaciones entre los artistas de la Fase 1. Realizadas en pares, procuran el cruce y discusión generacional. Estas sustituyeron las visitas de estudio. Se conversó sobre la forma en que la crisis sanitaria cambiará la producción y apreciación del arte y el panorama de ahora en adelante.

2. En sustitución del estudio abierto, se crearon "archivos abiertos", disponibles en la página web de la Bienal (www.bienaltlatelolca.org). El "archivo abierto" es un espacio virtual donde se muestran referencias, planos, dibujos, esquemas, videos, PDF's, gifs, audios, etcétera.

3. La realización de una publicación online, llamada 1521. La edición funciona en forma de un "códice virtual", donde cada participante replicó lo que en su momento hicieron los tlacuilos del Colegio de la Santa Cruz de Tlatelolco. Esto es, generar memoria histórica alrededor de un momento histórico de quiebre y regeneración cultural. IJ 


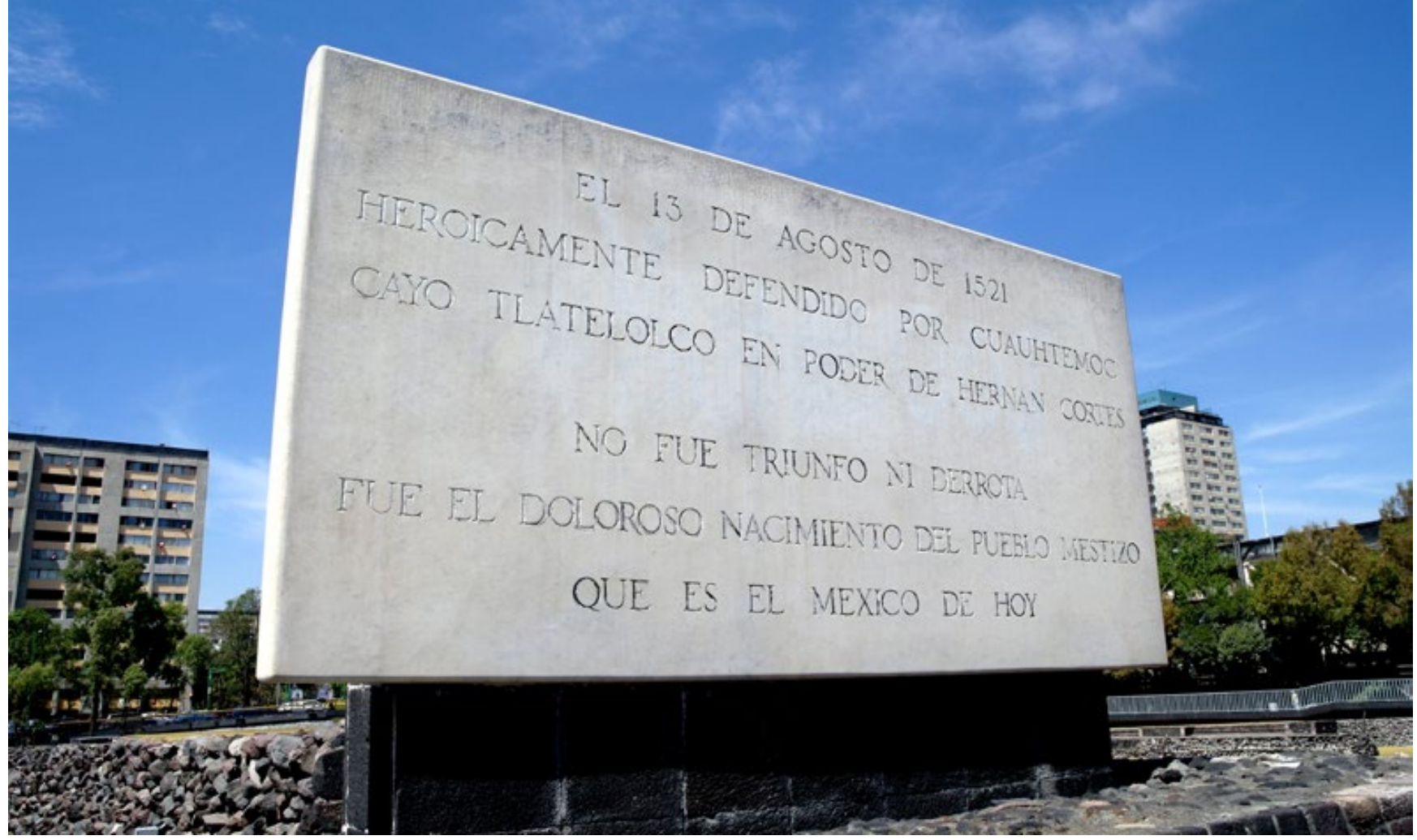

A Imagen 3. "Monolito en la plaza de las Tres Culturas". Monolito labrado con una frase de Jaime Torres Bodet que dice: "El 13 de agosto de 1521, $\checkmark$ Imagen 4. "Postal de Tlatelolco". Registro postal del proyecto Ciudad heroicamente defendido por Cuauhtémoc, cayó Tlatelolco en poder de Tlatelolco (1964). Hernán Cortés. No fue triunfo ni derrota, fue el doloroso nacimiento del pueblo mestizo que es el México de hoy".

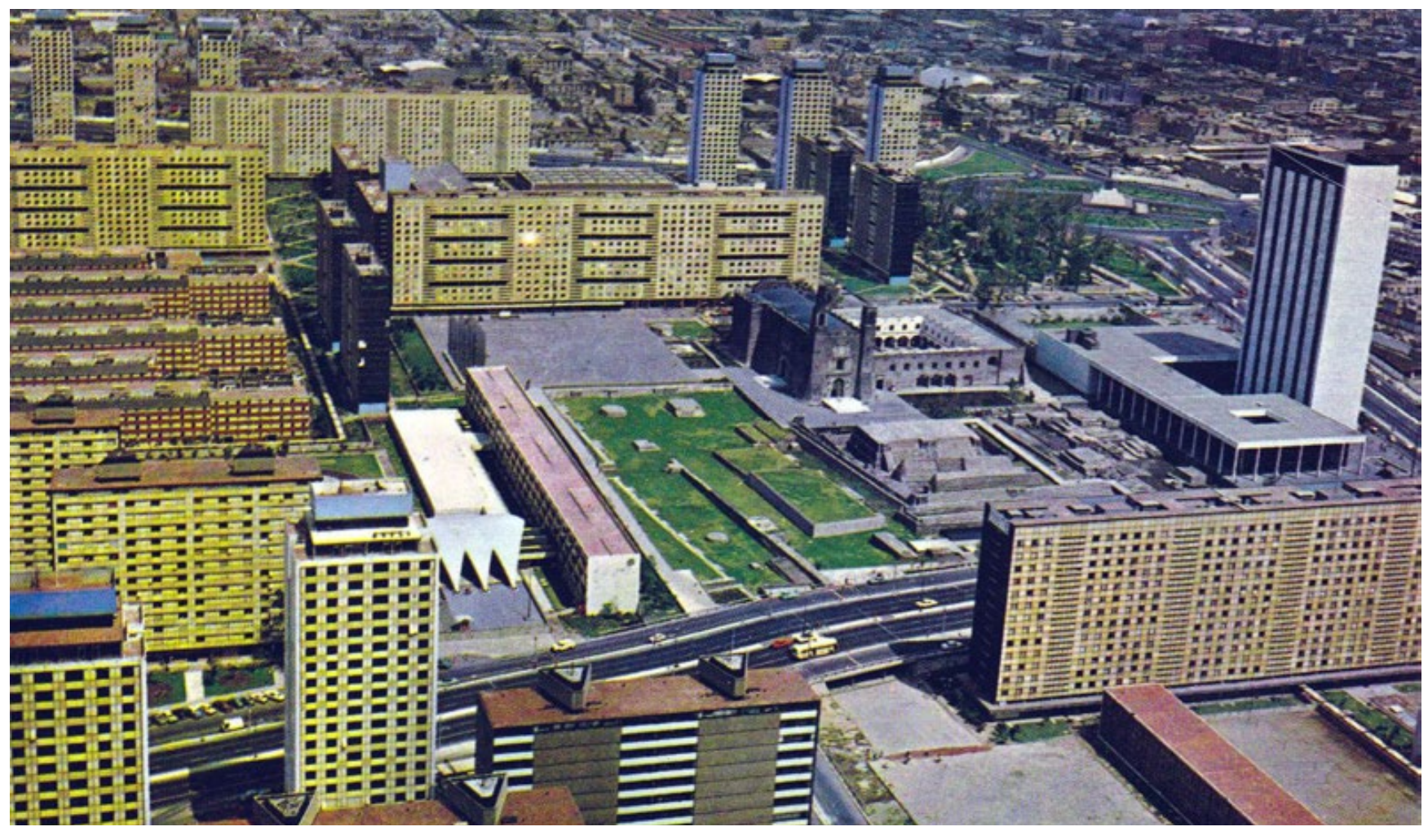




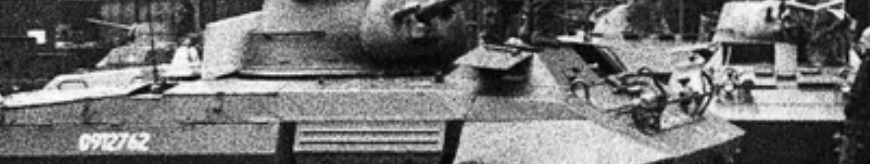

\section{a 15

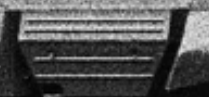 \\ 4 inent}

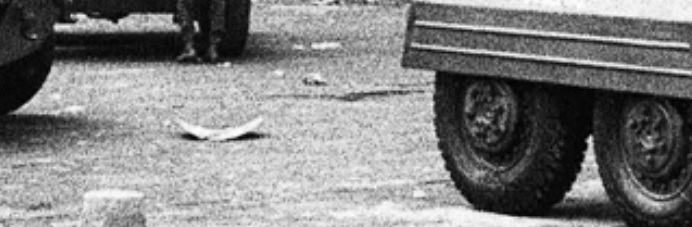

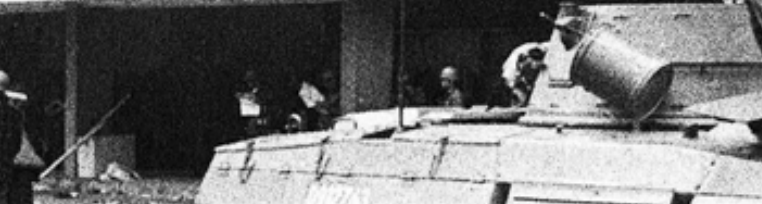

$\frac{5}{2}$

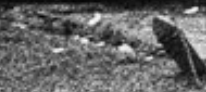

$78+2 x^{2}$

Th

$\bar{x}$

दिखें
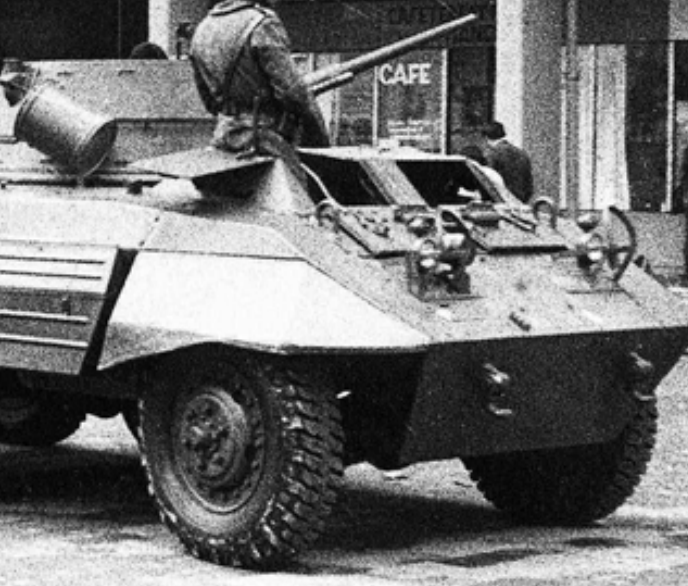

^ Imagen 5. "Tanquetas en la Plaza de las Tres Culturas". Mañana del 4 de

Octubre de 1968

en el edificio Nuevo León, en Tlatelolco, después del sismo de 1985.

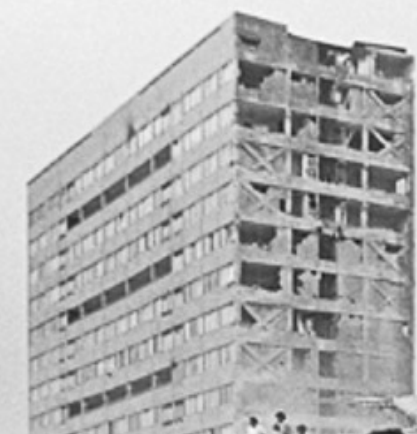

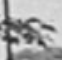

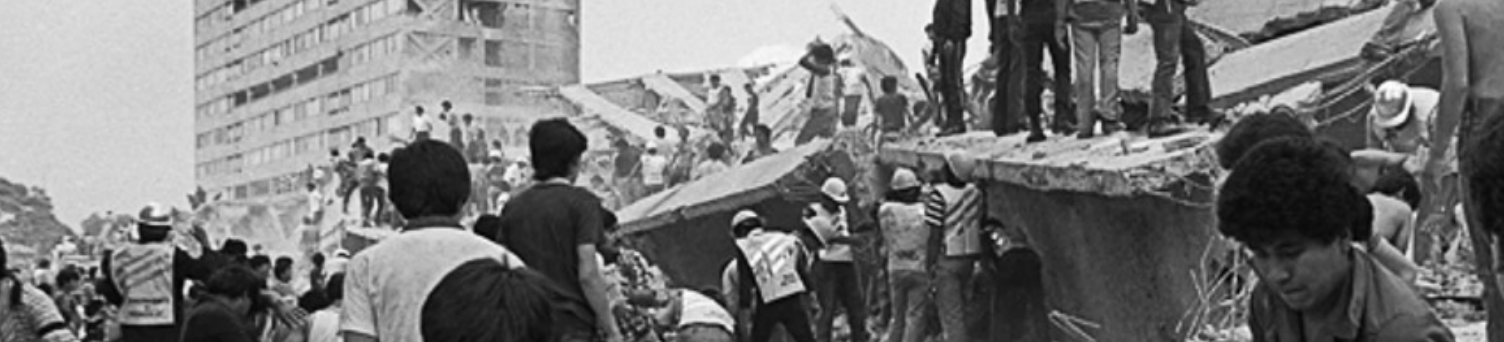

Site

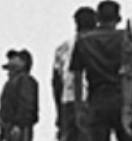

2)

A. $5=$

(2)

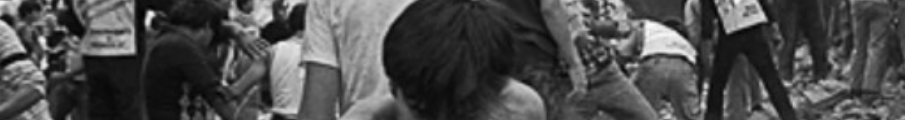

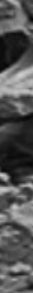

$7)^{2}$

हो)

b. 34 है

s.

38

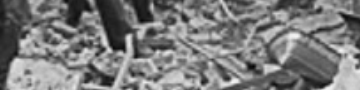

${ }_{4}-2 \times 125$

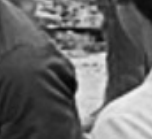

a)

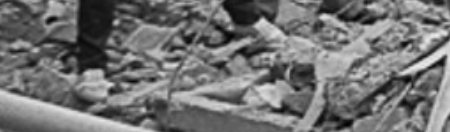

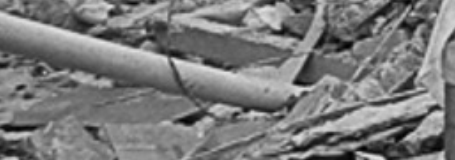

$x \rightarrow x^{2}$

1
5
5

3.

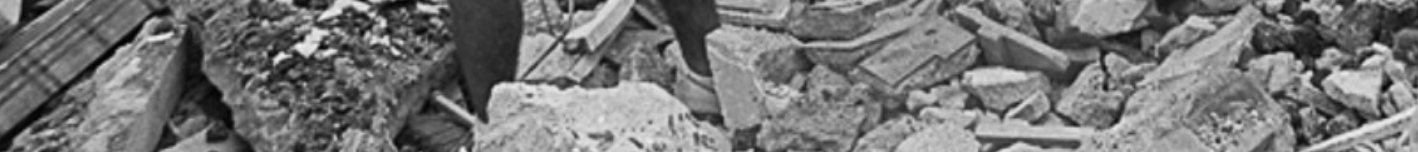



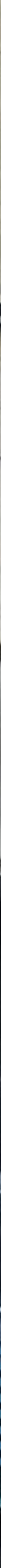

A Imagen 7. "Central de Maquetas". Fundada en 1952 por Manuel

Calderón y Gloria Salas. Su casa matriz se encuentra en la Torre 5 de

Febrero, en la $2^{a}$. Sección de Tlatelolco. Mariel Calderón y Emilio Zavala,

directores de Central de Maquetas, facilitaron el espacio de la tienda

para hospedar al proyecto Bienal Tlatelolca. 


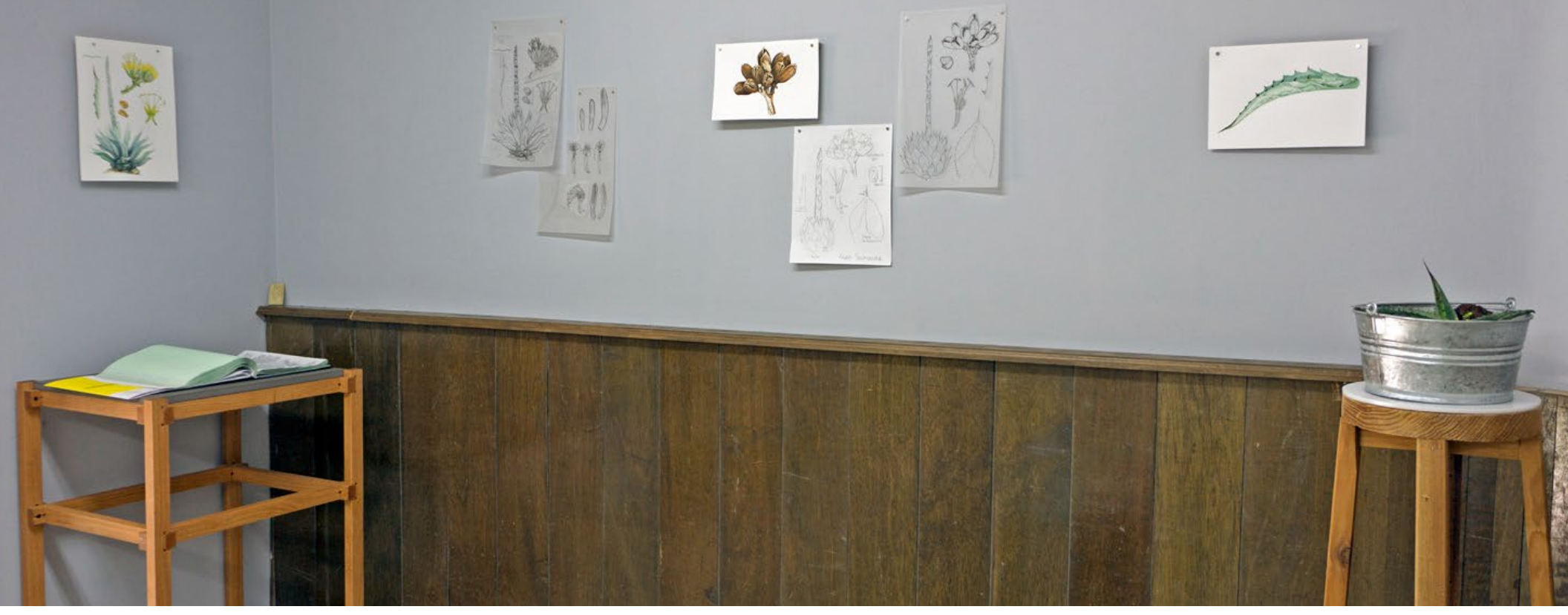

^Imagen 8. "Estudio Abierto". Estudio abierto de la artista Dulce Chacón (Ciudad de México, 1976).

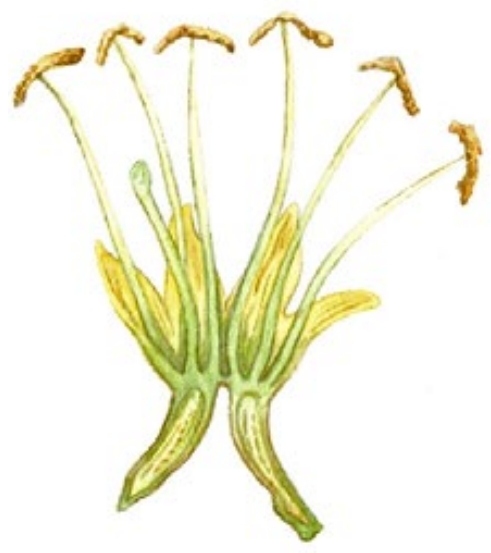

$\checkmark$ Imagen 9. Agave Salmiana. Ilustración. Dulce Chacón. Su residencia consistió en la búsqueda y clasificación de plantas medicinales, cultivadas o silvestres, en la $3^{\text {a }}$. Sección de Tlatelolco.

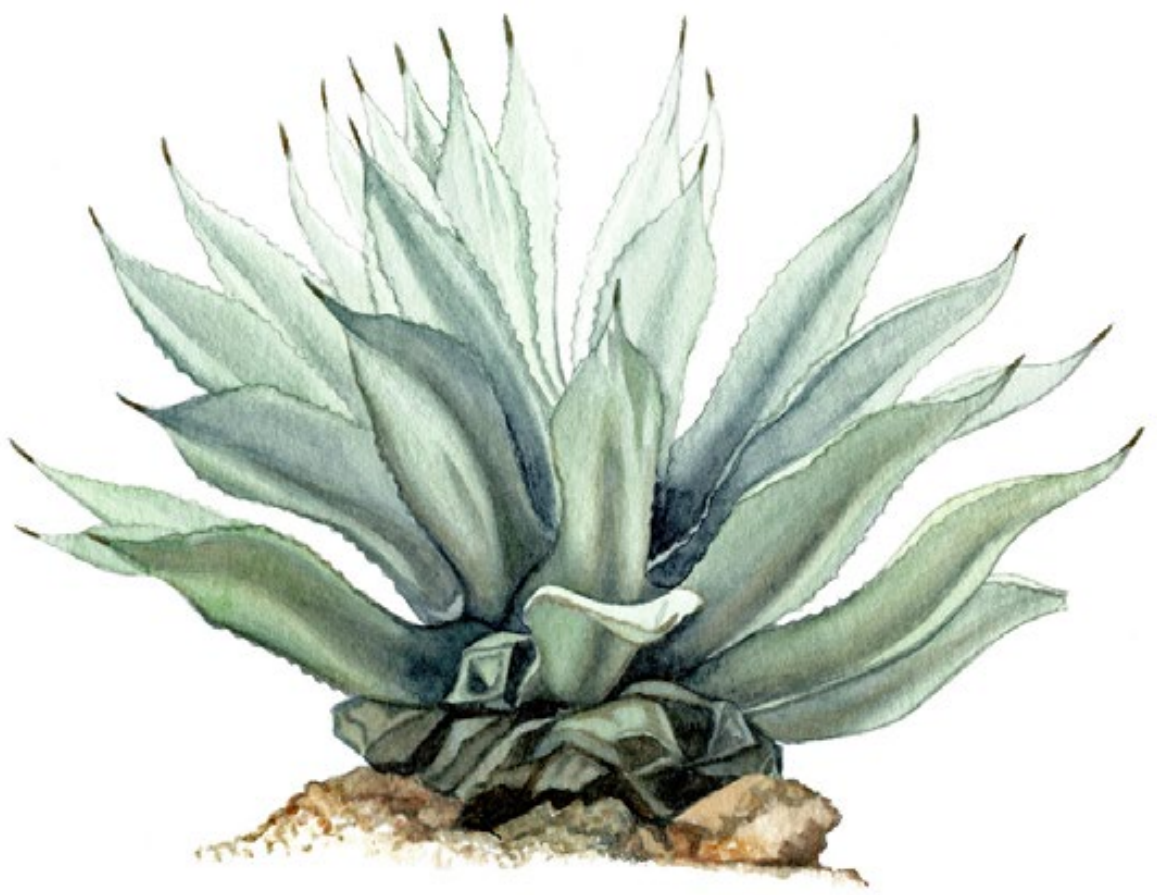



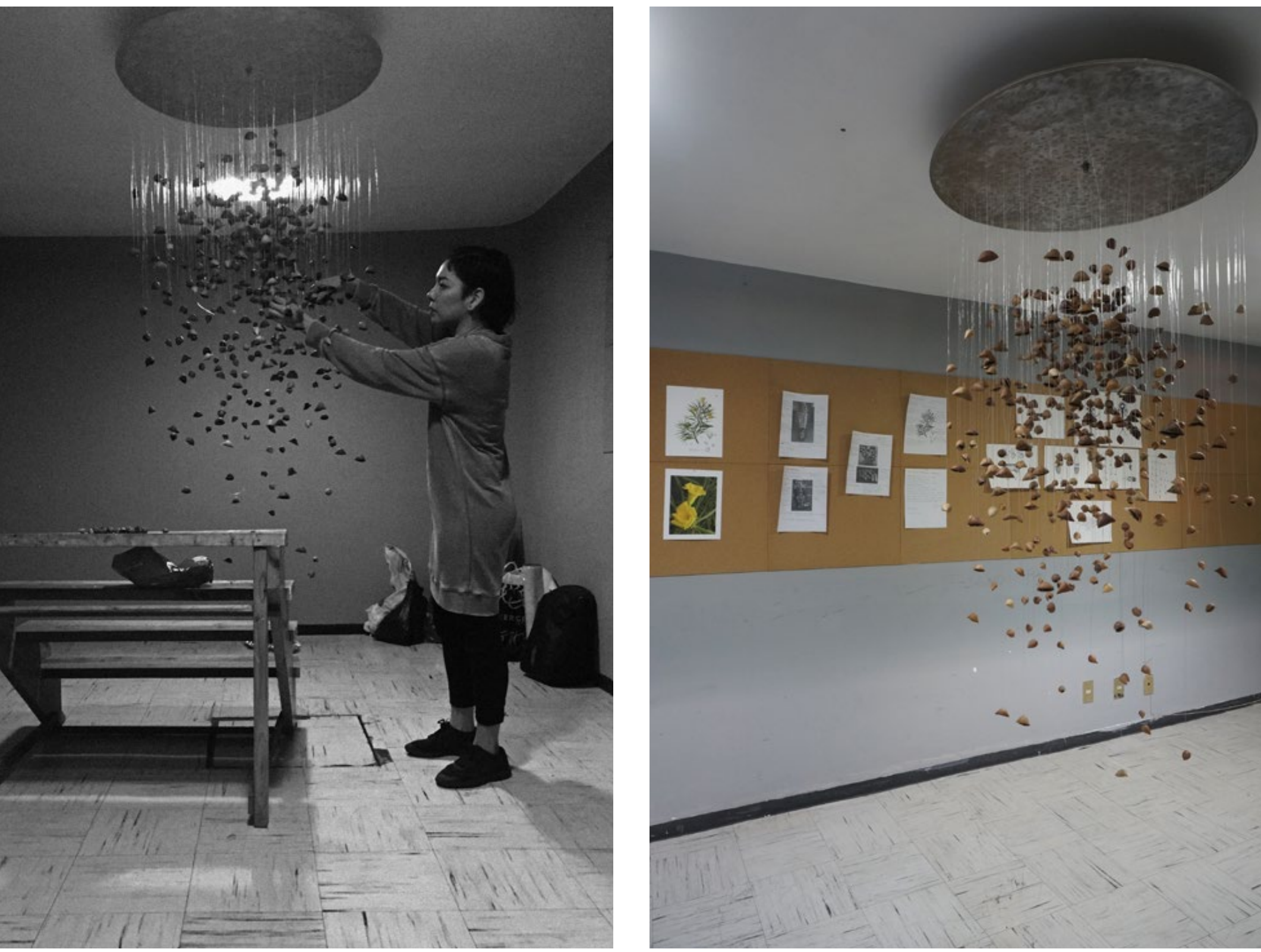

<Imagen 10. Lluvia. Montaje de escultura. Miriam Salado (2020).

$>$ Imagen 11. Lluvia. Escultura de Miriam Salado realizada con la semilla llamada "hueso de fraile". Miriam Salado. Su residencia se inspiró en los materiales contenidos en los accesorios de las danzas ceremoniales del centro de México con relación a las del norte del país. 


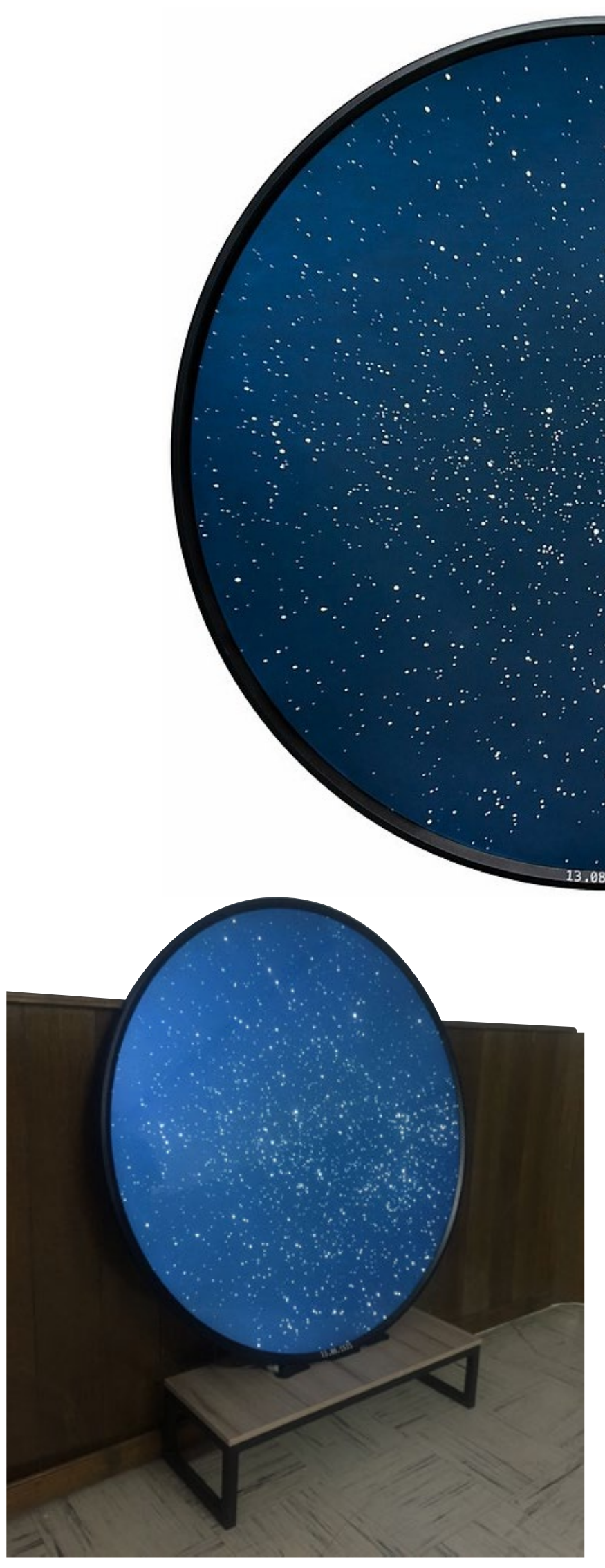

A Imagen 12. 13-08-1521. Simulación del cielo Tlatelolca la noche de su caída frente a las tropas españolas, el 13 de agosto de 1521. Mazenett \& Quiroga. El colectivo enfocó su investigación en la relación entre los distintos estratos históricos de Tlatelolco y la cosmovisión prehispánica.

<Imagen 13. 13-08-1521. Escultura. Mazenett \& Quiroga. Colectivo de artistas colombianos, residentes de la Bienal Tlatelolca de noviembre de 2019 a enero de 2020. 

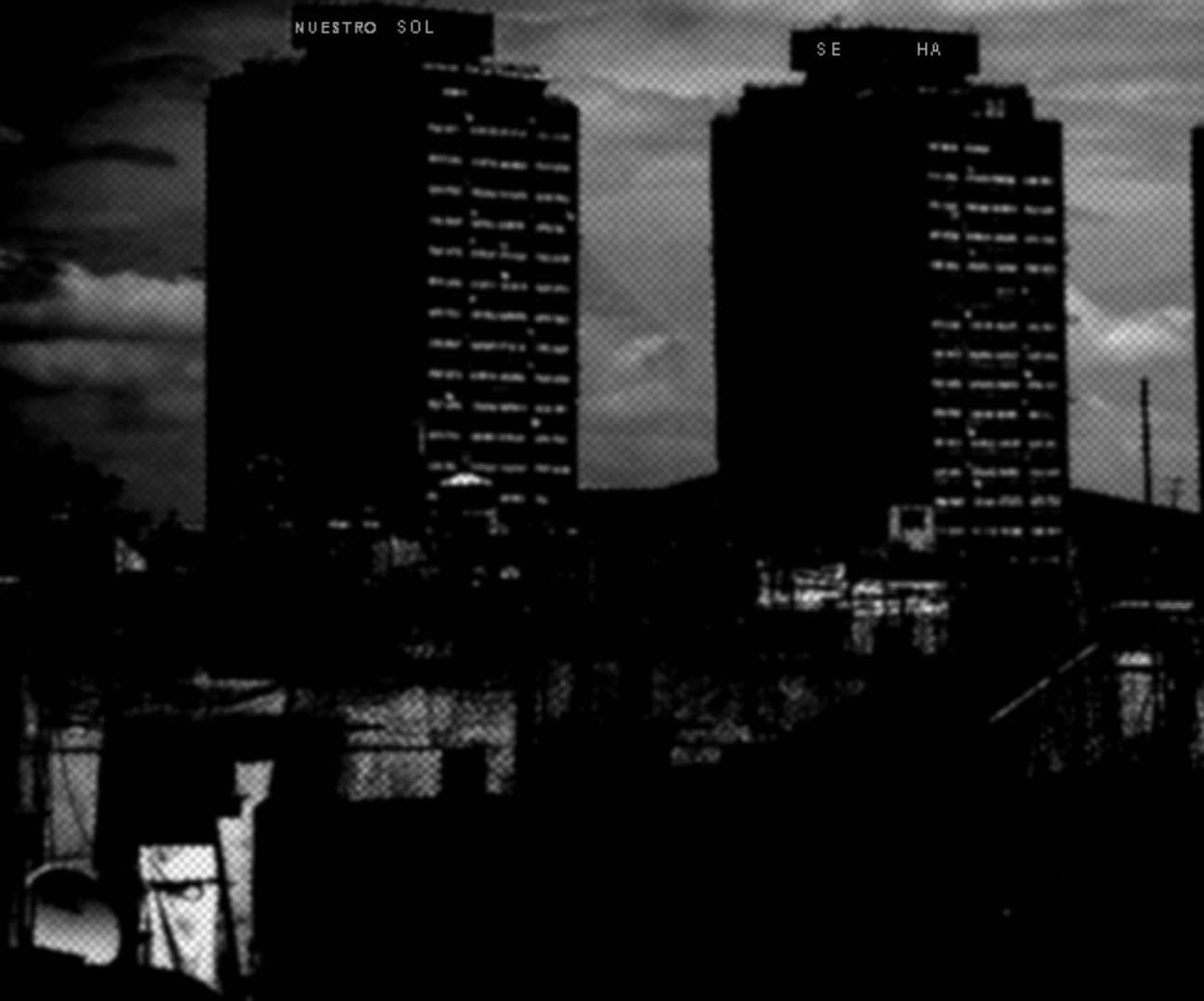

EXTINGUIDO

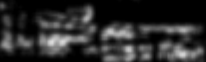

\section{intin}
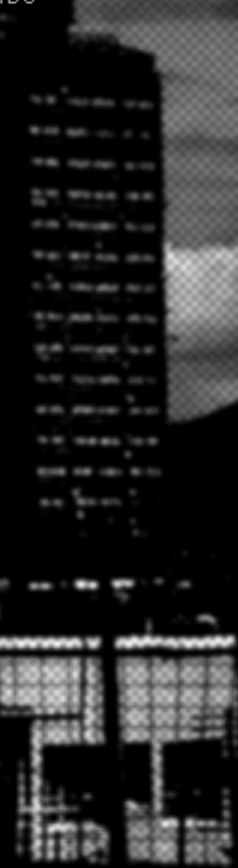

A Imagen 14. U.H. Tlatelolco, Estado Multinacional. Arturo Hernández

$\checkmark$ Imagen 15. Destruyamos nuestros recintos. Arturo Hernández Alcázar. Alcázar.

DESTRUYÁMOS ifl

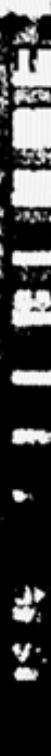
int of

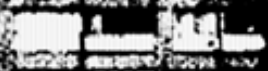
$=-2$ T incom

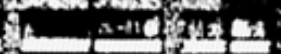

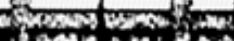
and ats 20 A contom ?

$\therefore$.

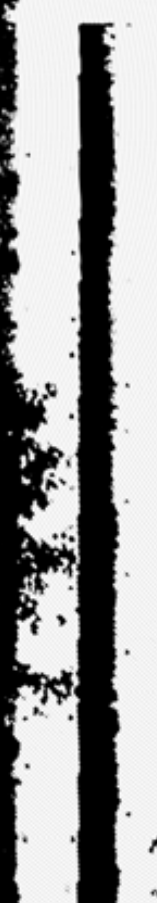

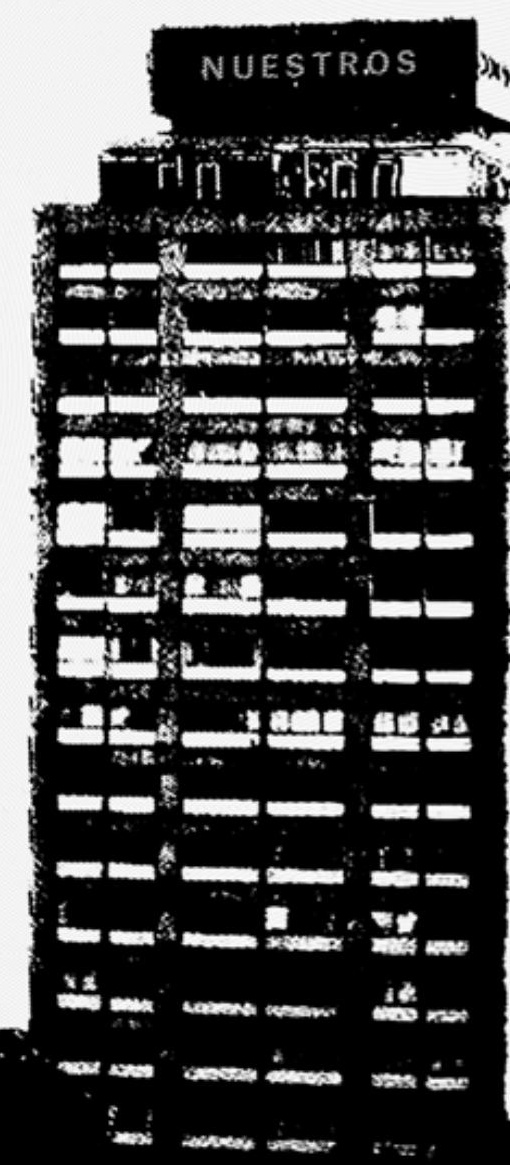

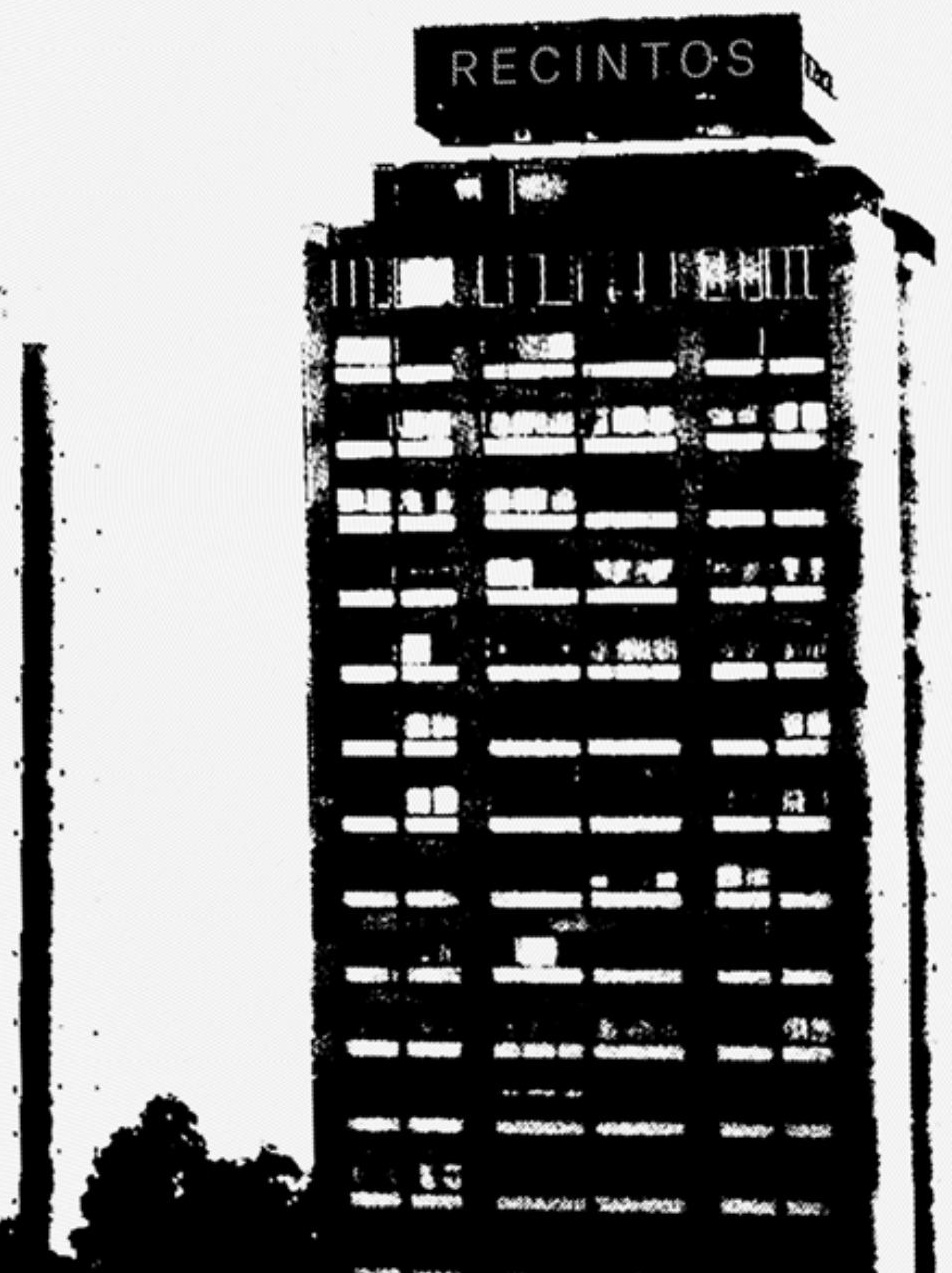




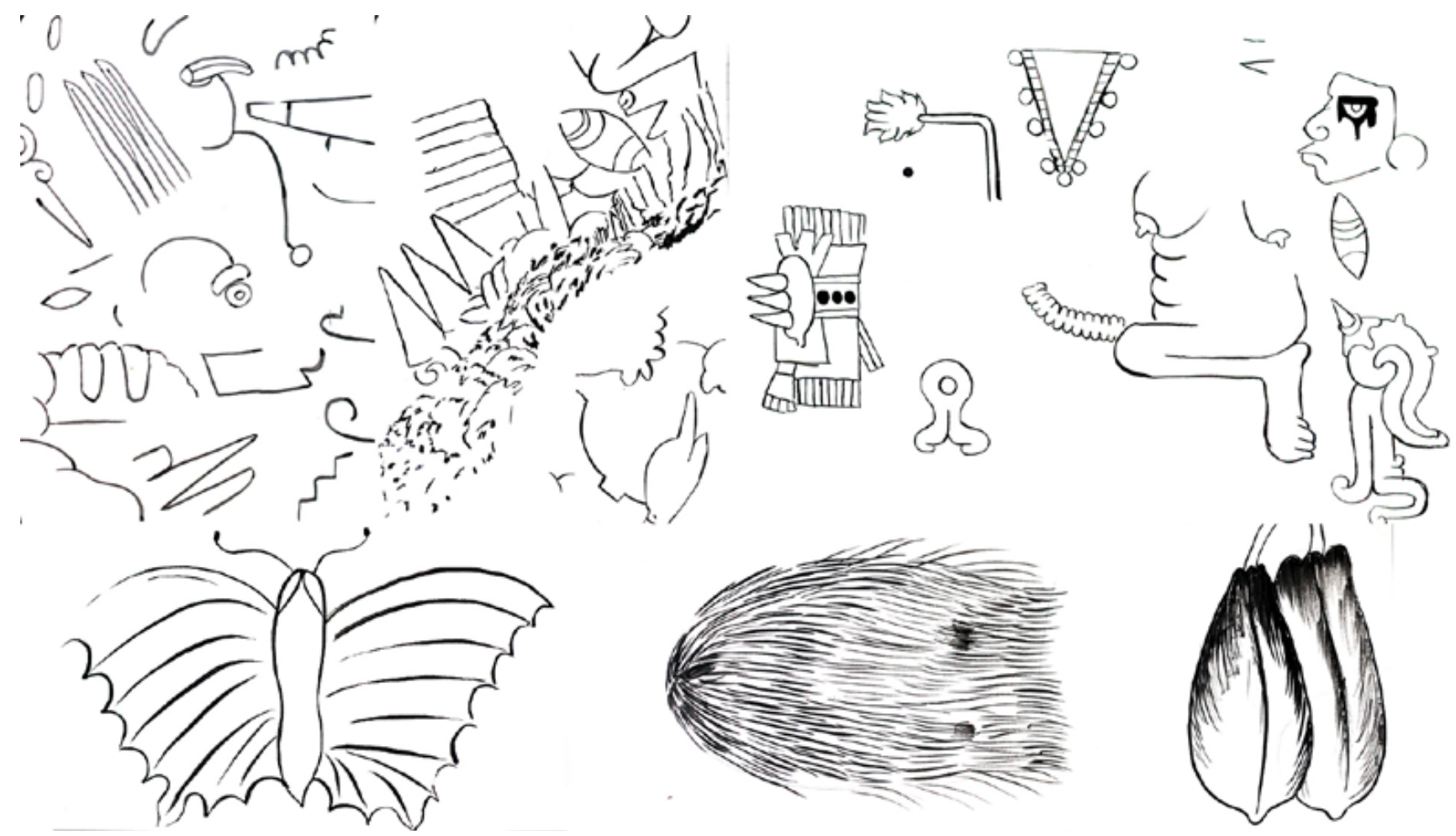

A Imagen 18. Dibujo de archivo. Erik Tlaseca. Su investigación gira en torno a los vacíos de Tlatelolco y la idea de abandono, pero también de memoria. $\checkmark$ Imagen 19. Silo. Propuesta de intervención. Laura Valencia Lozada. Su investigación desarrolla la noción de silo o semillero como metáfora de un contenedor de semillas-memorias, las de los habitantes de la Unidad Habitacional Tlatelolco.

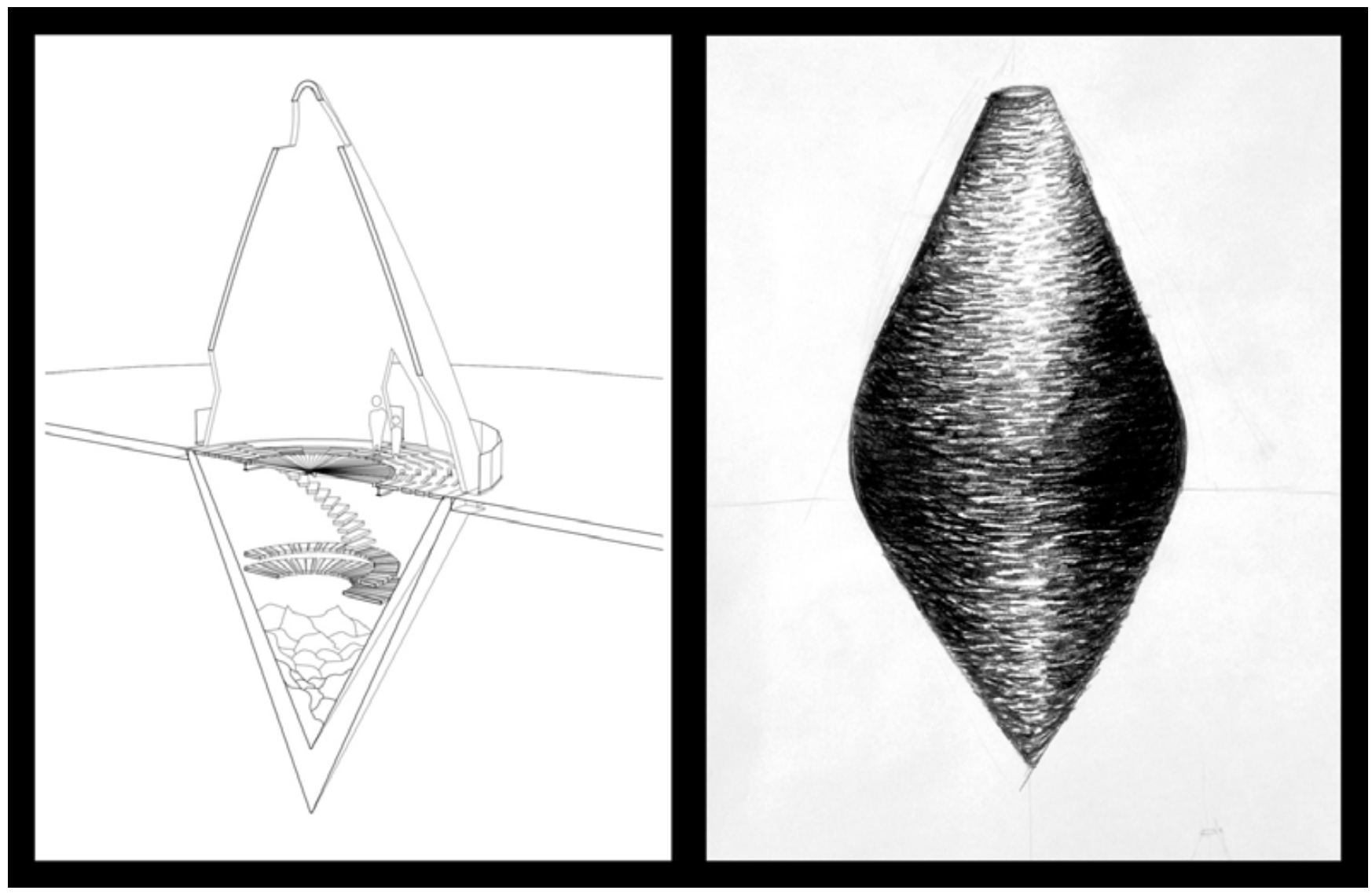




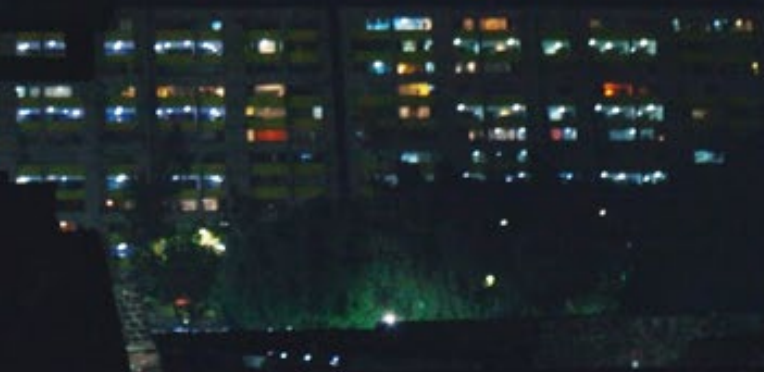

^Imagen 20. Vacío Fluorescente. Still de video. Erik Tlaseca.

$\checkmark$ Imagen 21. "Entrevista". Laura Valencia Lozada entrevistando al ingeniero Rubén Frola Jaime, quien estuvo en la Plaza de las Tres Culturas durante los hechos ocurridos el 2 de Octubre de 1968. 
Balam bartolomé (Ocosingo, Chiapas).

Estudió la Licenciatura en Artes Visuales (ENAP-UNAM), y egresado de la $1^{\text {a }}$ generación de Escuela Flora, en Flora Ars+Natura (Colombia, 2016). Fue beneficiario de la Fundación Pollock-Krasner (2016) y de la beca Jóvenes Creadores (2004). Tutor y docente de artes visuales en instituciones como SPF-Centro de la Imagen, SOMA, Centro ADM, Centro Cultural Border y PECDA-Chiapas.

Su trabajo procura la relación entre arte, naturaleza e historia y cómo las culturas contemporáneas se relacionan con su pasado. Se desarrolla en las disciplinas de escultura, video, fotografía, dibujo y escritura. Cuenta con exposiciones individuales y colectivas en Norte y Sudamérica, Europa y Asia.

Artista en residencia en Arte ERA (2007), ISCP (2009), NKD (2011), Bemis Center for Contemporary Arts (2014), Fundación Wabi (2015), Flora Ars+Natura (2016) y Sculpture Space (2017). Sus exposiciones individuales más representativas son Mexímoron, en el Museo Nacional de las Intervenciones (México, 2018) y Revés, en el Museo Carrillo Gil (México, 2014). Entre las colectivas la $1^{a}$ BIENALSUR (Argentina, 2017), $1^{\text {a }}$ Bienal de Bristol (Inglaterra, 2012) y $15^{\text {a }}$ Trienal de Tallin (Estonia, 2011).

Coordina, junto con Antonio Monroy, el proyecto de residencias e investigación artística Bienal Tlatelolca, en la Cd. de México.

ANTONIO MONROY (Toluca, 1984).

Licenciado en Artes Plásticas por la Universidad Autónoma del Estado de México. Fundador de Tlatelolco Central, y codirector de la Bienal Tlatelolca. Su trabajo, conjuga formas y conceptos del boxeo, con elementos clave del culto mesoamericano al agua, generando acciones colectivas, que reflexionan sobre el pensamiento indígena contemporáneo frente al despojo territorial. Obtuvo el Premio de Adquisición de la XI Bienal Monterrey FEMSA, becario del programa FONCA-CONACULTA Jóvenes Creadores (2012-2013). Formó parte de la residencia Ghost Days: Making Art for Spirit, dentro del programa Indigenous Arts, en Banff Centre for Arts and Creativity (Canadá, 2019), residente en Flora Ars+Natura (Bogotá, 2017), por parte del Ministerio de Cultura de Colombia. Vive y trabaja en la Ciudad de México. 